\title{
GEOPROCESAMIENTO APLICADO AL ANALISIS DEL USO DE LA TIERRA EN EL MUNICIPIO DE SAN PEDRO DE YCUAMANDYYÚ, PARAGUAY ${ }^{1}$
}

\section{GEOPROCESSING APPLIED TO LAND USE ANALYSIS ON SAN PEDRO DE YCUAMANDYYÚ, PARAGUAY}

\author{
Oscar Agustín Torres Figueredo $^{2}$ Pedro Roberto de Azambuja Madruga ${ }^{3} \quad$ Rudiney Soares Pereira $^{3}$
}

\section{RESUMEN}

El municipio de San Pedro de Ycuamandyyú está ubicado en el noroeste de la región oriental del Paraguay. Los objetivos de este trabajo constituyen la elaboración y el análisis del mapa del uso de la tierra para la planificación de actividades forestales en la zona, para los cuales se utilizaron técnicas de cartografía, sensores remotos y (SIG) Sistemas de Informaciones Geográficas, que posibilitaron el análisis de informaciones provenientes de imágenes satelitales LANDSAT TM 5, de cartas topográficas y de (GPS) Sistema de Posicionamiento Global, que permitió el procesamiento de datos en el programa Idrisi 2.0 para la confección de un mapa que posibilitó el análisis sobre la situación del uso de la tierra en el municipio. Se distinguió categorías predominantes como praderas altas o campos naturales, uso agropecuario y praderas bajas o bañados, siendo la cobertura forestal con valor inferior al $25 \%$. Se concluyó que el municipio presenta bastantes áreas de campos naturales y uso agropecuario que podrían utilizarse para actividades de reforestación, sea con especies nativas o exóticas de rápido crecimiento con la finalidad de obtener valores de cobertura forestal en equilibrio con las demás categorías de uso de la tierra.

Palabras-clave: sistemas de informaciones geográficas, uso de la tierra, imágenes satelitales.

\begin{abstract}
San Pedro of Ycuamandyyú is located in the northwest of the oriental region of Paraguay. The objectives of this work were the elaboration and the analysis of the map of the land use for the planning of forest activities in the place, for which were used techniques of cartography, remote sensing and (GIS) Geographical Information's Systems, that facilitated the analysis of information coming from satell ites images LANDSAT TM 5, topographical chart and (GPS) Global Position System, that allowed the processing of data in the program Idrisi 2.0 for the map manufactoring that facilitated the analysis on the situation of the land use in the municipality. Some predominant categories were distinguished as the high meadows or natural fields, agricultural use and low meadows, being the forest covering less than $25 \%$. As general conclusion the municipality presents enough areas of natural fields and agricultural use that could be used for reforestation activities, lither native or exotic species of rapid growth with the purpose of obtaining values of forest covering in balance with the other categories of land use.
\end{abstract}

Key words: geographic information system, landuse, satellites images.

\section{INTRODUCCIÓN}

La rápida disminución de los recursos forestales constituye hoy en día uno de los problemas ambientales y socio-económicos más relevantes del Paraguay y también del mundo. La pérdida de bosques, suelos, diversidad biológica y aguas, adquieren carácter dramático y desde el punto de vista ambiental presupone un obstáculo al desarrollo socioeconómico en general.

La degradación de los recursos naturales asociada normalmente a la poca o ninguna política de ordenamiento de las tierras ha provocado entre otros efectos, alteraciones significativas en el nivel de utilización y manejo de los sistemas productivos agrícolas, pecuarios y forestales, ocasionando

1. Parte de la disertación de Maestría presentada al Programa de Pós-Graduação em Engenharia Florestal, Centro de Ciências Rurais, Universidade Federal de Santa Maria.

2. Ingeniero Forestal, Profesor Investigador de la Facultad de Ciencias Agrarias, Universidad Nacional de Asunción, Paraguay. Casilla de Correo 1618, Campus Universitario, Asunción, Paraguay. ostorres28@yahoo.com

3. Ingeniero Forestal, Dr. Profesor del Departamento de Engenharia Rural, Centro de Ciências Rurais, Universidade Federal de Santa Maria, CEP 97105-900, Santa Maria (RS).

Recebido para publicação em 22/03/2002 e aceito em 11/10/2002. 
consecuencias negativas sobre la socioeconomía local. La inadecuada o desordenada ocupación de las tierras y la carencia de sistemas de manejo, favorecen los procesos que deterioran el suelo, cuyo reflejo es la disminución de la productividad y por consecuencia la calidad de vida de la población.

Las medidas de protección al medio ambiente en equilibrio con las condiciones de vida de la población rural deberían ser las prioridades en las políticas de uso y ocupación de las tierras, empezando en el ámbito de colonias y distritos, extendiéndose para la región y así llegar a escala nacional para tener un efecto significativo.

En este contexto los municipios pueden contribuir significativamente para lograr un uso adecuado de las tierras. Un eficiente ordenamiento de los recursos naturales traer á beneficios a corto, mediano y largo plazo para todos los sectores de la producción. Para alcanzar este fin son necesarias las informaciones de base sobre las potencialidades de las tierras que se pueden obtener a través de los sistemas de geoprocesamiento, herramientas muy importantes en los tiempos modernos. Con esto se consigue obtener valiosos recursos para una gestión, manejo e análisis de datos de un determinado lugar (Assad, 1998).

Para algunos autores como Rocha (1997), Morais (1997), Piroli (1999) y Costa (2000), la microcuenca hidrográfica representa la mejor unidad geográfica para la planificación integrada de los recursos naturales, por presentar una delimitación natural y no artificial. Sin embargo, el uso de una delimitación política en una determinada región también presenta sus ventajas desde el punto de vista de la ejecución de los proyectos, ya sean estos de conservación y/o de recuperación. Estos pueden ser más fácilmente implementados, cuando los mismos envuelven una única administración (Zanón, 2001).

En este sentido, el presente trabajo plantea con el apoyo de técnicas cartográficas, imágenes satelitales y de sistemas de información geográfica, el análisis de la ocupación y uso de la tierra de San Pedro de Ycuamandyyú, municipio del noroeste de la región oriental del Paraguay, para contribuir en su desarrollo sustentable.

\section{MATERIAL Y MÉTODOS}

El municipio de San Pedro de Ycuamandyyú se encuentra ubicado en el noroeste de la región oriental del Paraguay, entre las coordenadas geográficas de latitud sur $23^{\circ} 35^{\prime}$ y $24^{\circ} 15^{\prime}$ y de longitud oeste $57^{\circ} 30^{\prime}$ y $57^{\circ} 15^{\prime}$. Posee una superficie de $314.693,03$ ha. y está a una distancia de $400 \mathrm{Km}$. de la capital, Asunción. Limita al norte con la ciudad de Belén y está separada por el río Ypané. Al este con Tacuati, Nueva Germania y Lima, separados por los ríos Aguaray mi y Aguaray guazú. Al sur limita con San Pablo y Puerto Antequera separados por el río Jejui guazú. Al oeste limita con Puerto Antequera y Pozo Colorado del XV Departamento Presidente Hayes, éste último separado por el río Paraguay. El principal acceso a la ciudad es por la Ruta $\mathrm{N}^{\circ}$ XI Juana María de Lara, que une Puerto Antequera con Santa Rosa del Aguaray guazú, Nueva Germania. También se puede acceder al municipio por el camino que une Concepci ón con San Pablo. Otro acceso es por vía fluvial a través del río Paraguay y río Jejui guazú. Además de estas vías, el municipio posee una pista de aviación.

En cuanto a los aspectos socioeconómicos del lugar según datos de la municipalidad, San Pedro está dividido en 40 compañías o distritos en la zona rural y en 9 barrios en la zona urbana. Los principales rubros de la producción agrícola son: algodón, naranja, maíz, maní, mandioca, poroto, banana, caña de azúcar, sorgo, siendo el sésamo y la planta medicinal cedrón Paraguay (Lippia citrodora - Verbenaceae) los productos de renta más importantes. La producción pecuaria es eminentemente ganado vacuno de corte y de leche, producidos en grandes establecimientos, así como ganado equino, porcino y aviar en pequeña escala. Los productos forestales del lugar son madera aserrada y madera bruta en rollos explotados totalmente de los bosques nativos remanentes del lugar. Otros productos forestales como leña, carbón y yerba mate son producidos en pequeña escala como alternativas a la agricultura y comercializados en su mayoría en el lugar. La población económicamente activa (PEA) en 1992 era de 8.275 habitantes distribuidos en 7.234 hombres y 1.041 mujeres. De acuerdo al Censo de Población y Viviendas de 1992, San Pedro tenía una población total de 28.940 habitantes, de los cuales $4.642(16,04 \%)$ se encontraban en el área urbana y $24.292(83,96 \%)$ en el área rural. La densidad demográfica era de 8,4 habitantes por $\mathrm{Km}^{2}$ (Paraguay, 1993).

El clima del lugar según la Dirección de Hidrología y Meteorología, dentro de la clasificación de 
Köppen es de tipo Cfa, subtropical húmedo, con temperatura media de máximas de $34,8{ }^{\circ} \mathrm{C}$ y mínimas de 10 ${ }^{\circ} \mathrm{C}$. La temperatura media anual es $23^{\circ} \mathrm{C}$, siendo que la pluviosidad media anual es de $1.350 \mathrm{~mm}$. Los meses más lluviosos son abril, mayo y de setiembre a diciembre; los meses más secos son junio, julio y agosto, siendo estas características irregulares en los últimos años debido a cambios en el régimen de lluvias de la zona (UNA, 1995).

El mapeamiento de reconocimiento de las unidades de suelos de la región oriental del Paraguay, en escala de trabajo de 1/100.000, publicación de mapas en escala 1/500.000, y siguiendo las normas de clasificación de suelos de Soil Taxonomy, López Gorostiaga et al., (1995) determinaron las siguientes unidades: (A1) Alfisol Typic Albaqualf, (A7) Alfisol Aquic Paleudalf, (A12) Alfisol Mollic Paleudalf, (U10) Ultisol Rhodic Paleudult, (U11) Ultisol Typic Paleudult, (U16 Ultisol Ochreptic Hapludult, (E6) Entisol Aquic Udifluvent (E6) y (TMO) Tierras Misceláneas.

Según UNA (1994), la vegetación del departamento de San Pedro en 1991, tenía 460.317 ha. de bosques nativos, representando $23 \%$ de la superficie total del mismo. Esta cobertura forestal nativa se dividía en "bosques altos continuos", que son masas forestales de distribución continua, constituidas por árboles altos que emergen en un dosel dominante, con alturas entre 25 y 35 metros, en superficies con más de 500 ha. y con especies de alto valor comercial, y "bosques altos degradados", que son asociaciones forestales de composición florística similar a la anterior, pero muy deteriorada y sometida a una gran presi ón de uso agropecuario. Normalmente las especies económicamente valiosas fueron prácticamente eliminadas, dominando árboles de 15 a 25 metros de altura. Los bosques altos continuos poseían 355.049 ha. y la formación bosques altos degradados 105.268 ha..

Además de estas formaciones vegetales UNA (1994), menciona que el departamento posee formaciones naturales de gramíneas, denominadas "praderas altas", localizadas generalmente en lugares de topografía alta, por encima de los niveles de máxima inundación. Otras formaciones naturales de interés y con grandes áreas dentro del departamento son las "praderas bajas", con vegetación localizadas en lugares de topografía plana y/o valles afectados por las aguas de inundación durante ciertas épocas del año. Los suelos de estos lugares tiene el nivel freático superficial y de lento drenaje. En algunas áreas los suelos pueden estar afectados, de manera casi permanente por las aguas de inundación durante todo el año; en este caso son denominadas "praderas bajas inundadas", sucediéndose principalmente en las proximidades de los ríos Paraguay y Jejui guazú.

De acuerdo a López et al. (1987), los bosques nativos albergan muchas especies de valor comercial tales como Tabebuia ipe (tajy), Cedrela fissilis (cedro), Pelthophorum dubium (yvyrá pytá), Balfourodendron riedelianum (guatambú), Enterolobium contortisiliquum (timbó), Parapiptadenia rigida (kurupa'y), Astronium fraxinifolium (urunde'y), Pterogyne nitens (yvyrá ró), entre otros.

En los bosques altos degradados las especies dominantes pertenecen a las familias Laur áceas, Mirtáceas y Meliáceas. Los bosques nativos son los más susceptibles a los cambios en el uso de la tierra, ya que fué explotada primeramente para la producción de madera por aserraderos y posteriormente habilitada para la producción agrícola y/o pecuaria (UNA, 1995).

Los materiales utilizados en el estudio fueron Cartas topográficas de nomenclatura 5474 Concepción, 5574 Tacuati, 5473 Yvapobo, 5573 Nueva Germania, 5472 San Pedro de Ycuamandyyú y 5572 General Elizardo Aquino en escala 1/100.000 como base para georeferenciar la imagen orbital y digitalización de las curvas de nivel, de la red de drenaje y la red vial. Imagen de Satélite del sistema LANDSAT - 5 TM, órbita / punto 226/76 y 226/77, bandas 3, 4, 5, de fecha 3 de marzo de 1997. Computadores Pentium III $600 \mathrm{MHz}$, y Pentium II $350 \mathrm{MHz}$. Los aplicativos computacionales utilizados fueron Idrisi for Windows 2.0 para el procesamiento de las imágenes. Para la obtención de archivos vectoriales de curvas de nivel, red de drenaje, red vial y polígono máscara del municipio, fue utilizado el SITER 6.0 (Sistemas de Informações Territoriais), desarrollado por el Profesor Dr. Enio Giotto, del departamento de Ingenieria Rural de la Universidad Federal de Santa Maria (Brasil). El Adobe Photoshop 5.5 se utilizó para la unión de las imágenes de los puntos / orbitas, separación en bandas e indexado de las imágenes citadas. La edición final de los diferentes mapas para el municipio se realizó en el Programa CorelDraw 9.0. Para la construcción de tablas y gráficos fueron utilizados los Programas Excell y Word 
2000. Para el trabajo de (CGP) Ground Control Point o Puntos de Control en el Terreno fue utilizado un GPS (Sistema de Posicionamiento Global) Magelin 2000.

Siguiendo la metodología definida por Libault (1971) apud Zanón (2001), para análisis geográficos, el trabajo se desarrolló basado en las siguientes etapas:

La primera etapa consiste en el nivel compilatorio, en la cual se colecta materiales para la realización del estudio propuesto, así como su selección, llevando en consideración su valor y significando con relación al tema abordado.

En la segunda etapa del trabajo o nivel correlativo, se ejecutó la correlación entre los datos anteriormente seleccionados. Esta correlación constituye los cruzamientos de los diferentes planos de información generando nuevos elementos de análisis.

En la tercera etapa o nivel semántico, se realizó la interpretación de los datos obtenidos en la fase anterior. Con base a esta interpretación se generan los resultados finales del trabajo y las respectivas conclusiones.

En la cuarta y última etapa del trabajo, denominado normativo, se procedió a la confección de mapas finales, con el objetivo de traducir de forma más sencilla y visual los resultados de los procesos anteriormente llevados a cabo.

Determinado el área de estudio fue necesario obtener las imágenes orbitales del sistema LANDSAT - 5 TM que recubriese el municipio. Teniendo las imágenes se procedió a la unión de los puntos / orbitas 226/76 y 226/77 así como el corte de los cuadrantes de interés para obtener una nueva imagen. Posteriormente a esta imagen se insertó bandas 3, 4 y 5 en los canales B, G, R. En el Idrisi 2.0 se seleccionó el área de interés a través de la visualización en la pantalla y se definió las coordenadas que abarcaba el municipio, derivadas del procesamiento en el SITER 6.0 y mediciones en las cartas topográficas.

Se realizó el proceso de georeferenciado de las imágenes composición falso color. Para esto fueron determinadas las coordenadas de puntos homólogos en las cartas topográficas y su correspondiente en la imagen falso color. Estos puntos de control usados en este proce dimiento pueden ser observados en la Tabla 1 .

TABLA 1: Lista de las coordenadas utilizadas para georeferenciar la imagen.

TABLE 1: Coordinates list used to georeference the image.

\begin{tabular}{|c|c|c|c|c|}
\hline $\begin{array}{c}\text { Puntos } \\
\text { de } \\
\text { Control }\end{array}$ & $\begin{array}{c}\text { Coordenada } \\
\text { x } \\
\text { Antigua } \\
\end{array}$ & $\begin{array}{c}\text { Coordenada } \\
\text { y } \\
\text { Antigua } \\
\end{array}$ & $\begin{array}{c}\text { Coordenada } \\
\text { x } \\
\text { Nueva (UTM) }\end{array}$ & $\begin{array}{c}\text { Coordenada } \\
\text { y } \\
\text { Nueva (UTM) }\end{array}$ \\
\hline Punto 1 & 2776.978 & 1227.131 & 528869.5 & 7354048.0 \\
\hline Punto 2 & 741.2493 & 2566.823 & 473917.7 & 7403522.0 \\
\hline Punto 3 & 1684.913 & 420.827 & 491600.0 & 7335100.0 \\
\hline Punto 4 & 2736.46 & 1790.787 & 530213.1 & 7370882.0 \\
\hline Punto 5 & 378.1272 & 1834.589 & 459351.8 & 7383608.0 \\
\hline Punto 6 & 1672.391 & 344.5276 & 490804.4 & 7332848.0 \\
\hline Punto 7 & 105.0353 & 2473.794 & 454465.5 & 7403579.0 \\
\hline Punto 8 & 818.0917 & 2169.565 & 474342.9 & 7391425.0 \\
\hline Punto 10 & 2522.231 & 642.5258 & 518432.9 & 7338068.0 \\
\hline Punto 11 & 2821.737 & 1191.346 & 530603.0 & 7352079.0 \\
\hline Punto 12 & 2441.911 & 1219.196 & 518780.4 & 7355441.0 \\
\hline Punto 13 & 708.0596 & 2486.449 & 472616.4 & 7401547.0 \\
\hline Punto 14 & 1737.431 & 1936.437 & 501239.7 & 7380046.0 \\
\hline Punto 15 & 2377.45 & 620.2997 & 513877.5 & 7337598.0 \\
\hline Punto 16 & 2057.538 & 870.4559 & 505513.0 & 7347011.0 \\
\hline
\end{tabular}

Después se procedió a la delimitación del municipio de San Pedro de Ycuamandyyú, derivada del SITER y exportadas a Idrisi para su correspondiente generación de la imagen. Luego se realizó el proceso 
de clasificación del uso de la tierra, en las cuales fueron definidas 6 diferentes clases de uso: Bosques, Praderas altas (campos naturales), Praderas bajas, (Bañados), Uso Agropecuario, Suelo expuesto y Agua. La identificación de las clases fue efectuada a través de una preclasificación visual de la imagen en la pantalla de la computadora. Se hizo necesaria también la utilización de una clase especial para representación del área urbana del municipio, completando así 7 categorías de uso.

Para el trabajo de CGP fue utilizado un GPS de navegación Magelin 2000, consistiendo en la colecta de coordenadas en un área conocida y representativa del uso de la tierra del municipio, las cuales sirvieron de base para la obtención del mapa de uso de la tierra a través de proceso conocido como clasificación digital supervisada en el Idrisi 2.0.

Los archivos vectoriales referentes a la red de drenaje y red vial fueron digitalizados en pantalla, sobre las cartas topográficas en escala 1:100.000. Esto se efectuó a través del Programa SITER 6.0, que posteriormente fueron convertidos en formato $V E C$ para ser importados para Idrisi 2.0 en el mismo sistema de coordenadas de la imagen.

\section{RESULTADOS Y DISCUSIÓN}

\section{Composición falso color y Carta Imagen}

El primer resultado del procesamiento de las imágenes es la obtención de una imagen composición falso color donde se asocia las bandas 3, 4 y 5 del sistema LANDSAT TM 5. Presentó una buena diferenciación entre los diferentes usos de la tierra del municipio de San Pedro de Ycuamandyyú. En la composición falso color se asocia el color azul a la banda 3, por tanto el agua y otras clases de uso que poseen humedad tuvieron una mayor reflectancia y se asoció al color azul. La banda 4 se asoció al color verde, y por tanto todo tipo de vegetación demostró una mayor reflectancia en los tonos verdes. La banda 5 asociada al rojo presenta colores en tonalidades rojas, debido a que el suelo y otras clases de uso de la tierra presentaron mayor reflectancia en esta tonalidad. La asociación de imágenes con las informaciones referentes a la red de drenaje, red vial, localidades y coordenadas es llamada de "Carta Imagen" pues hay una asociación de los elementos comunes de las cartas topográficas con imágenes, en el caso del satélite LANDSAT 5 TM. La Figura 1 muestra la composición falso color en la Carta Imagen del municipio.

\section{Uso de la tierra}

En la Figura 2 y en la Tabla 2 se presentan la clasificación del uso de la tierra con sus siete (7) categorías de uso, las cuales son las de mayor relevancia. Dichas categorías son: Bosques, Praderas altas (campos naturales), Praderas bajas (Bañados), Agropecuario, Suelo expuesto, Agua y Área urbana.

TABLA 2: Áreas ocupadas y participación de cada categoría de uso de la tierra, en el municipio de San Pedro de Ycuamandyyú, Paraguay.

TABLE 2: Occupied areas and participation of land use category in San Pedro de Ycuamandyyú, Paraguay.

\begin{tabular}{l|c|c}
\hline \multicolumn{1}{c|}{ Categorías de Uso } & Área (ha) & Área (\%) \\
\hline Bosques & $48.015,94$ & 15,26 \\
Praderas Altas & $111.195,84$ & 35,34 \\
Praderas Bajas & $54.140,98$ & 17,20 \\
Agropecuario & $93.796,09$ & 29,81 \\
Suelo expuesto & $4.312,51$ & 1,37 \\
Agua & $2.902,72$ & 0,92 \\
Área urbana & 328,96 & 0,10 \\
\hline Total & $314.693,03$ & 100,00 \\
\hline
\end{tabular}

Analizando las categorías de uso de la tierra en un área total de 314.693,03 ha., se tiene que las clases dominantes de la misma son las Praderas Altas o campos naturales $(35,34 \%)$, uso Agropecuario $(29,81 \%)$; las Praderas Bajas $(17,20 \%)$, y Bosques $(15,26 \%)$. Las otras categor ías de uso que ocupan menor proporción son suelo expuesto $(1,37 \%)$, agua $(0,92 \%)$ y área urbana $(0,1 \%)$. El hecho se puede explicar porque el municipio presenta una tendencia de explotación agrícola y ganadera en áreas ocupadas 
anteriormente por bosques y/o campos naturales y también por una relación con los tipos de suelos predominantes del lugar.
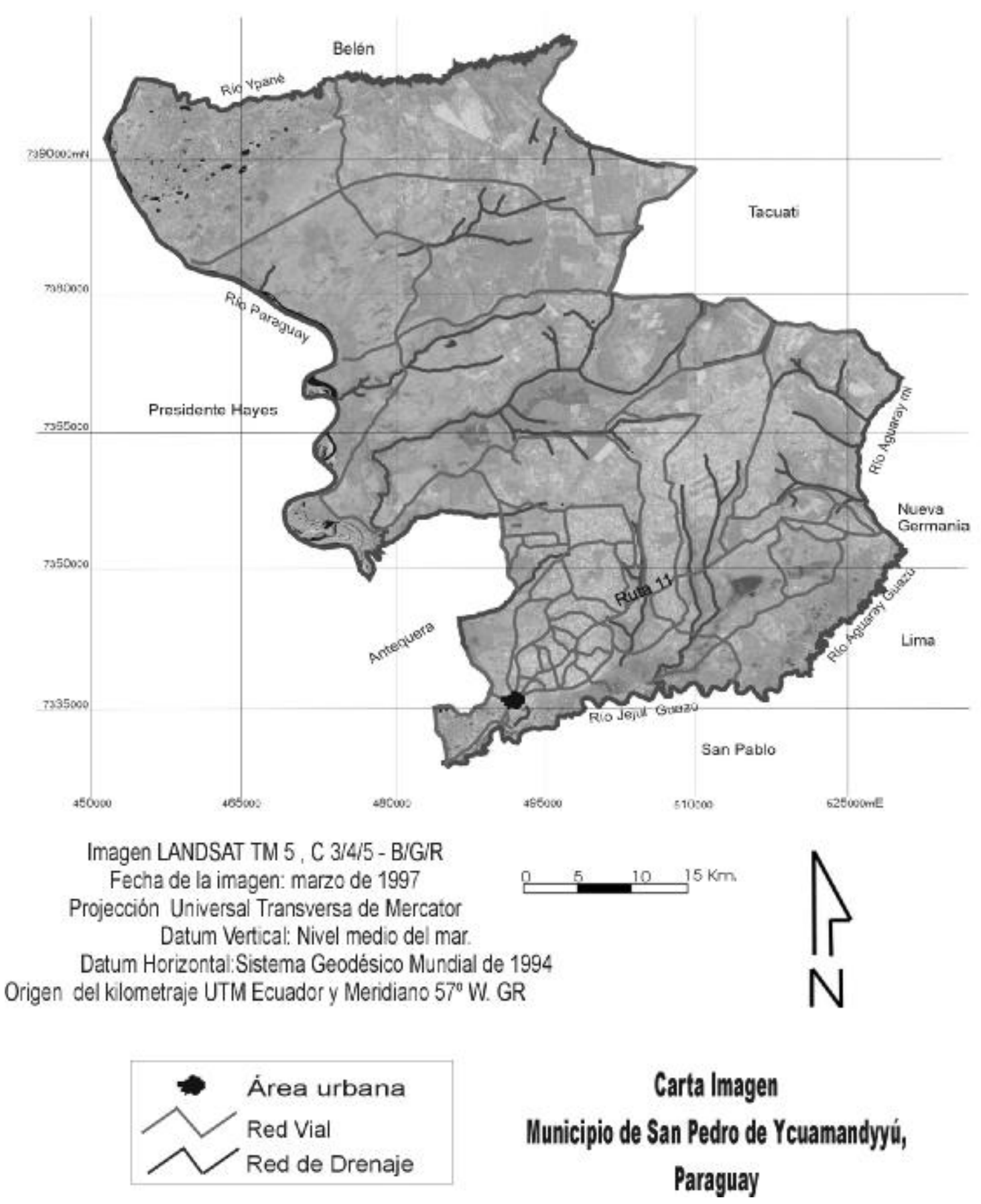

FIGURA 1: Imagen LANDSAT TM5, 1997, Municipio de San Pedro de Ycuamandyyú, Paraguay. FIGURE 1: The LANDSAT TM5, 1997 image, San Pedro de Ycuamandyyú, Paraguay.

Espacialmente según la Figura 2, las praderas altas se localizan más próximas al río Paraguay, mientras que las praderas bajas se localizan más próximas al río Jejui guazú, Aguaray guazú y en el centro del municipio. Las praderas altas están localizadas en lugares de topografía alta, por encima de los niveles 
de máxima inundación, en tanto que las praderas bajas están situadas en lugares de topografía plana y/o valles afectados por las aguas de inundación durante ciertas épocas del año. Las dos categorías de uso se caracterizan por presentar un relieve plano a suavemente ondulado, suelos arcillosos, vegetación de gramíneas mezclados con algunos bosques bajos y palmas.

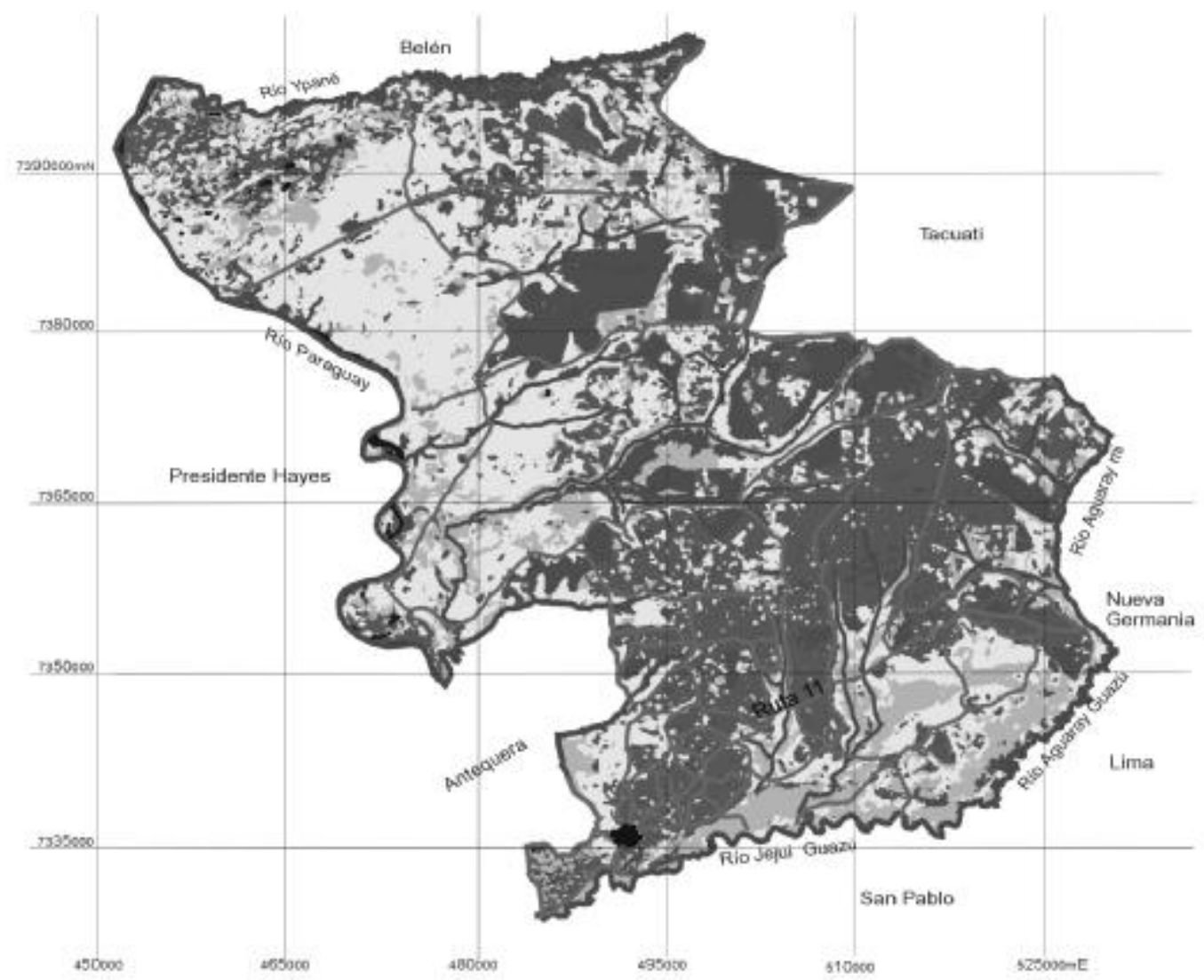

Mapa de Uso de la Tierra

Clasificación Digital Supervisada Imagen LANDSAT TM 5, C 3/45 * BIG/R

Fecha de la imagen: marzo de 1997

Projección Universal Transversa de Mercaior

Datum Vertical: Nivei médio del mat.

Datum Horizontal Sistema Geodésico Mundial de 1994

Origem del kilometraje UTM Ecuador y Meridiano $57^{\circ} \mathrm{W}$. GR
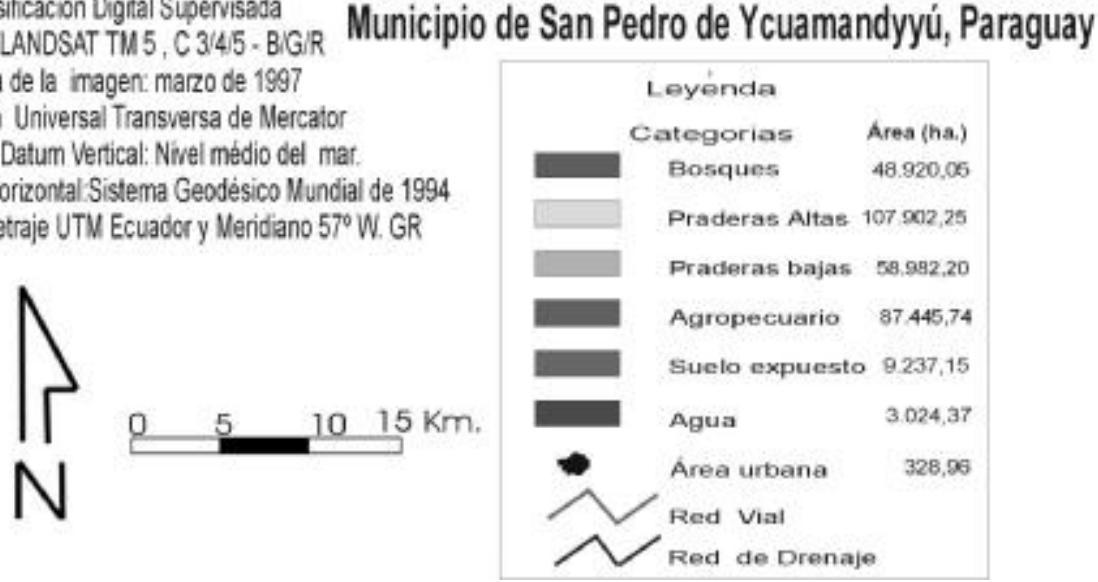

FIGURA 2: Mapa del Uso de la Tierra, Municipio de San Pedro de Ycuamandyyú, Paraguay.

FIGURE 2: Land use map, San Pedro de Ycuamandyyú, Paraguay.

La categoría de uso Agropecuario de acuerdo a la Figura 2, se extiende por todo el municipio, localizándose en extensión más próximas al centro urbano y a la ruta XI. El sistema de producción de esta categoría de uso es generalmente en minifundios con cultivos agrícolas de subsistencia (agricultura 
familiar) como poroto, maíz, maní, mandioca, caña de azúcar, batata, entre otros. Los cultivos comerciales generalmente son algodón, banana, tabaco, naranja, yerba mate y algunas superficies con s ésamo y Cedrón Paraguay (Lippia citriodora), comercializados en su mayoría dentro del municipio. La producción pecuaria es eminentemente de cría de ganado vacuno para carne, equino y en menor proporción ganado porcino y aviar, siendo estos últimos rubros de producción generalmente familiar. La producción agrícola y pecuaria presentan bajos niveles de actualización de los sistemas de producción, siendo este factor una de las causas del deterioro ambiental y que se refleja en la calidad de vida de la poblaci ón rural.

La categoría de uso Bosques con 48.015,94 ha, representa 15,26\% del total del municipio. De acuerdo a la Figura 2, se localiza más al centro y norte del municipio. Esto se debería particularmente porque en esta parte las fronteras agrícolas y ganaderas todavía no han ejercido una presión considerable y porque las propiedades rurales son generalmente latifundios. La explotación de madera nativa del municipio es efectuada en las grandes propiedades, nuevas colonias agrícolas habilitadas en los últimos años, así como en algunos bosques de los minifundios. Se caracteriza generalmente por el aprovechamiento de pocas especies y la falta de un plan de manejo regulador de los mismos. La oferta de madera de valor come rcial está quedando cada vez más escasa, necesitando conservar las pocas áreas de bosques nativos. Los bosques localizados próximos al río Ypané y su confluencia con el río Paraguay son del tipo bosques alto degradados y/o del tipo ribereño citados por UNA (1994). Desde el punto de vista de la producción de madera no posee gran importancia; sin embargo es interesante desde el punto de vista de refugios ecológicos para la vida silvestre. Cabe destacar que esta área ha sido incluida como sitio RAMSAR en la lista de humedales de importancia internacional, bajo la denominación de "Estero Milagros". Son formaciones únicas en el país comprendiendo pequeñas lagunas, pastizales naturales, bosques bajos, sabanas arboladas y peque ños esteros, muy importantes para las aves migratorias y animales asociados a los ambientes acu áticos.

Rocha (1991) determina que según las normas de la FAO sobre cobertura forestal, el área mínima que debería tener una microcuenca hidrográfica es de $25 \%$ de su área total, para conseguir un ambiente ecológicamente equilibrado. Este porcentaje debería estar principalmente ubicado en las regiones más altas de la microcuenca (coronas). La ley forestal $422 / 73$ de Paraguay también prevé este porcentaje para las propiedades rurales mayores de 25 ha..

Este parámetro es interesante y es aplicable según el mismo autor para unidades políticas como el municipio en estudio, ya que el mismo solo posee 15,26\%. Un área de 31.469,303 ha,, lo que corresponde un $10 \%$ del total de la superficie sería de prioridad para reforestación con el fin de alcanzar el mínimo especificado por FAO.

Todavía Burgos Sosa (1994) define que "tierras de uso exclusivamente forestal" son aquellas que presentan limitaciones de grado elevado y en forma permanente, represe ntando una alta fragilidad, por lo que resultan inadecuados para otros usos que no sea el forestal. El mismo autor comenta que las características de estas tierras son suelos ribereños de lagos, lagunas, pantanos, arroyos y ríos con influencia de la napa freática, pendiente menores de $2 \%$, con deficiencia de aireación todo el año y con riesgo de inundación frecuente, características descritas también por López Gorostiaga et al. (1995) en el levantamiento de suelos de la región oriental del Paraguay.

Según la Tabla 2, la categoría de uso Suelo expuesto con 4.312,51 ha., (1,37\% del total del municipio) pertenece a áreas en preparación para labores agropecuarias. La categoría Agua con 2.902,72 ha, representa $0,92 \%$ del total del área en estudio y está representado por lagunas, arroyos y ríos que están distribuidas por todo el municipio conforme Figura 2. El aprovechamiento de los mismos es para recreación y pesca. Además constituyen refugios de gran importancia de la vida silvestre del lugar. La categoría de uso Área urbana, con 328,96 ha. (0,10\% del municipio), es la representación del centro de las actividades socioeconómicas, situándose en él todas las instituciones sociales de importancia de la vida cotidiana del municipio.

Teniendo en cuenta todas las consideraciones antes citadas, se puede afirmar que el municipio posee gran potencial de superficies que pueden ser destinadas para las actividades forestales, sean como Reservas de las áreas con bosques en las propiedades de latifundios y en lugares con humedales, manejo de los bosques remanentes en los minifundios a través de enriquecimiento con especies nativas y la reforestación con especies nativas o exóticas de rápido crecimiento tanto en las praderas altas como en los de uso 
agropecuario para poder conseguir alcanzar el mínimo de cobertura forestal requerido por FAO.

\section{CONCLUSIONES}

El uso de técnicas de cartografía asociadas a la teledetección y geoprocesamiento, mostraron ser eficientes en la obtención de mapas digitales que pueden ser manipulados con facilidad y rapidez. El uso de la tierra en el municipio de San Pedro de Ycuamandyyú esta constituido básicamente por las praderas altas, uso agropecuario y las praderas bajas, siendo que las otras categorías de uso presentan valores bien menores al 2\% del municipio. La cobertura forestal es de 48.015,94 ha, (15,26\% del total del municipio), siendo este valor menor que las normas de la FAO. Para alcanzar el $25 \%$ de cobertura forestal se podría priorizar programas de manejo de los bosques que todavía se encuentran en el municipio, así como destinar superficies de praderas altas y uso agropecuario para reforestaciones con especies nativas o ex óticas. En general, todo el municipio posee potencial para la producción forestal siendo que todavía cuenta con los ríos Paraguay y Jejui guazú como alternativas de transporte de productos para los grandes centros de consumo del país y del MERCOSUR.

\section{AGRADECIMIENTOS}

Se agradece especialmente al Laboratorio de Geoprocesamiento de la Carrera de Ingenier ía Forestal (CIF) de la Facultad de Ciencias Agrarias (FCA) de la Universidad Nacional de Asunción (UNA) por la concesión de las imágenes satelitales y materiales cartográficos.

Al intendente municipal Eduardo Vera Bejarano por el apoyo durante el levantamiento de campo.

A los profesores y colegas del Laboratorio de Geoprocessamento del Departamento de Engenharia Rural de la Universidade Federal de Santa Maria, Rio Grande do Sul, Brasil por permitir usufructuar sus instalaciones para la realización del trabajo.

\section{REFERENCIAS BIBLIOGRÁFICAS}

COSTA, F. A., Da Aplicação de geoprocessamento na análise e modelagem ambiental da microbacia Arroio Passo do pilão: Estudo de adequação de uso da terra relacionada aos sistemas agrícolas. 2000. 90p. Dissertação (Mestrado em Engenharia Agrícola) - Universidade Federal de Santa Maria, Santa Maria.

ASSAD, M.L.L. Sistemas de informações geográficas na avaliação da aptidão agrícola das terras. In: ASSAD, E.D.; SANO, E.E. Sistemas de informações geográficas: aplicações na agricultura. 2. ed. Brasília: EMBRAPASPI/EMBRAPA-CPAC, 1998. p. 171-196.

BURGOS SOSA, S. M. Definición de tierras exclusivamente forestales de la región oriental del Paraguay. Ka'aguy, Asunción, v.10, n.1, p. 8-9, 1994.

LÓPEZ GOROSTIAGA, O.; GONZALEZ, E.; MOLINAS, O. et al., Mapa de reconocimiento de suelos de la Región Oriental. Asunción : MAG / SSERNMA - BID. 1995, Escala 1/500.000.

LOPEZ, J.A., et al. Árboles comunes del Paraguay: ñande yvyrá mata kuera. Asunción: Cuerpo de Paz, 1987. 425p. (Colección e intercambio de información).

MORAIS, S.M. de J., Diagnósticos quantitativos mínimos de ambiência para o manejo integrado da sub-bacia hidrográfica do arroio Cadena, Município de Santa Maria - RS. 1997, 135p. Dissertação (Mestrado em Engenharia Agrícola) - Universidade Federal de Santa Maria, Santa Maria.

PARAGUAY. Atlas Censal. Asunción: Secretaria Técnica de Planificación - Dirección General de Estadísticas, Encuestas y Censos, 1993. 145p.

PIROLI, E.L. Sistema de informação geográfica e imagen de satélite para análise do uso da terra na microbacia do arroio do meio - Santa Maria. 1999, 77p. Dissertação (Mestrado em Engenharia Agrícola) - Universidade Federal de Santa Maria, Santa Maria.

ROCHA, J. S. M. da. Manual de projetos ambientais. Santa Maria: Imprensa Universitária, 1997. 718p.

. Manual de manejo integrado de bacias hidrográficas. 2. ed. Santa Maria: Ed. UFSM, 1991. 76p.

UNIVERSIDAD NACIONAL DE ASUNCIÓN (UNA). Uso de la tierra y deforestación en la región oriental del Paraguay Periodo 1984-1991. Asunción, 1994. 31p.

UNIVERSIDAD NACIONAL DE ASUNCIÓN (UNA) Atlas ambiental de la región oriental del Paraguay. Asunción, 1995. v. 2.

ZANON, P.C.F. Geoprocessamento aplicado ao planejamento e analise do uso da terra no município de Ivorá RS. 2001, 156p. Dissertação (Mestrado em Engenharia Agrícola) - Universidade Federal de Santa Maria, Santa Maria. 